\title{
Diagnostics of the Macroeconomic Environment on the Subject of Generation of Financial Risks
}

\author{
Arthur Panasyuk, Mikhail Shatokhin* , Maria Bulavina, and Lyubov Dedusheva \\ Institute of World Civilizations, Moscow, Russian Federation
}

\begin{abstract}
The study presents the results of diagnosing the macroeconomic environment for the generation of financial risks. The author substantiates the relevance and necessity of regular monitoring of macroeconomic indicators in terms of their impact on the volatility of the probability of systemic financial risks. The paper analyzes the main indicators of the functioning of the credit, foreign exchange, financial, money markets, as well as the basic characteristics of the state of the economic system of Russia. The performed diagnostics of the main indicators of the country's financial system development makes it possible to form a comprehensive opinion on the intensity of the influence of the macroeconomic environment on the generation of financial risks..
\end{abstract}

\section{Introduction}

The presence of financial risks is an integral part of the functioning of any business entity under the existing market conditions. At the same time, the probability of a particular financial risk to a certain extent depends on the volatility and dynamics of the main macroeconomic indicators. The state of the domestic financial market and other indicators of the development of the national economic system have the most significant impact on the level of financial risks. In this regard, it can be concluded that the macroeconomic environment is inherently the main generator of systemic financial risks. Diagnostics of the state of the macroeconomic environment makes it possible to identify the most relevant systemic risks that may affect the results of commercial activities of institutional units of the national economy. The existing conditions for the development of economic processes in Russia are characterized by an increased degree of turbulence in the impact of macroenvironmental factors. The noted variability of the country's financial sector is due to the general instability in the global financial markets caused by the pandemic, the negative impact of external economic sanctions, as well as the presence of certain internal factors of the systemic crisis [1]. These circumstances increase the relevance of regular monitoring of the macroeconomic environment for the generation of financial risks of a systemic nature.

The purpose of this study is to diagnose the macroeconomic environment in Russia for the generation of financial risks. Achievement of this goal is based on the results of solving the following list of tasks:

\footnotetext{
${ }^{*}$ Corresponding author: shato-hinm@mail.ru
} 
- to substantiate the relevance and directions of diagnostics of the macroeconomic environment for the generation of financial risks;

- carry out diagnostics of the macroeconomic environment in Russia for the generation of financial risks;

- to form a comprehensive assessment of the state of the macroeconomic environment in terms of generating financial risks.

The methodological basis for the implementation of this work was a number of general scientific research methods, among which it is necessary to highlight research, monographic, formal-logical, analytical synthesis, scientific abstraction, statistical, economic-analytical, groupings, selective observation. The use of this set of methods contributes to the solution of the tasks in the work, and also allows for a comprehensive diagnosis of the macroeconomic environment in Russia for the generation of financial risks. The results of the conclusions formed within the framework of the study and the revealed patterns can be used to remove uncertainty in the processes of identification and management of financial risks, including at the microeconomic level.

\section{Results and discussion}

The existing conditions for the development of the world economy in general and the economic system of Russia in particular contribute to the formation of a whole range of financial risks of a systemic nature. Within the framework of this study, we will perform diagnostics of the main areas of the macroeconomic environment that contribute to the generation of financial risks. First of all, it becomes necessary to assess the general macroeconomic dynamics of the development of the country's economic system. The key indicator that can be used to solve this problem is the value of GDP, the dynamics of which is revealed in Figure 1. The study of the general dynamics of GDP allows one to judge not only the vector of development of the national economy and possible investment risks. The slowdown in the rate of economic development of the country as a whole generates an increase in the likelihood of investment risks due to the level of return on investment.

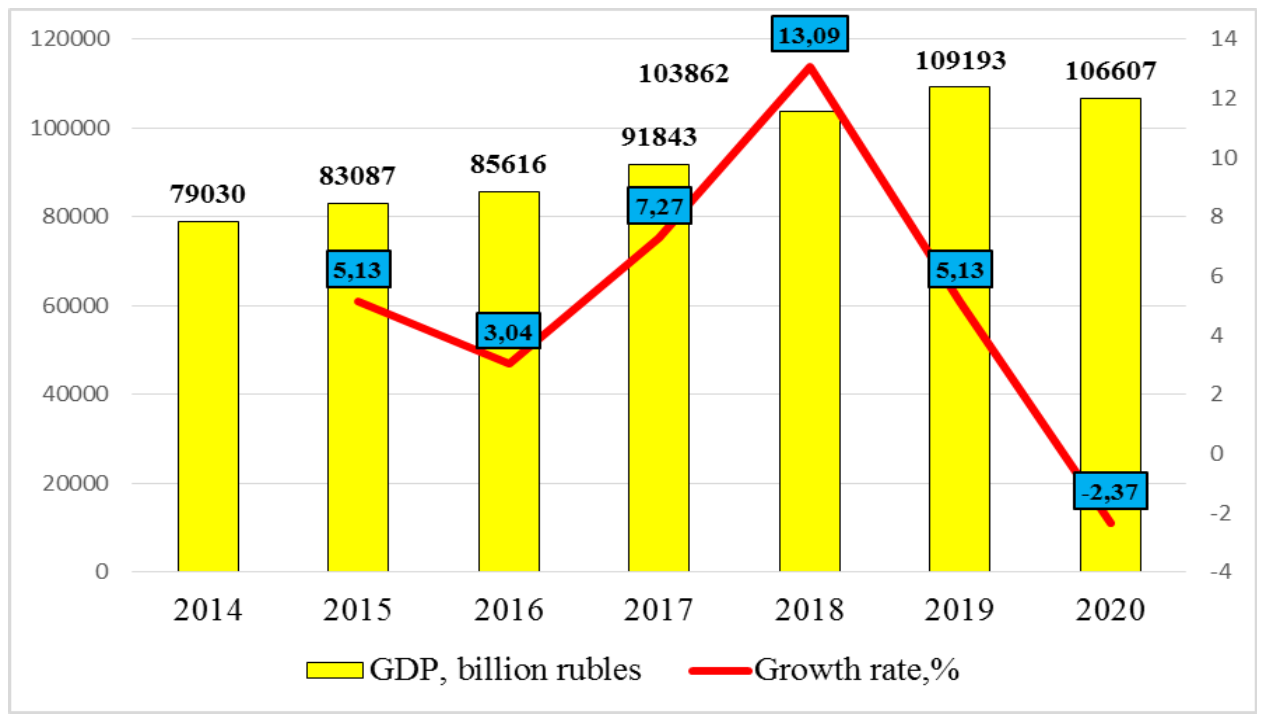

Fig. 1. Dynamics of Russia's GDP

Source: Official website of the Federal State Statistics Service. - URL: https://rosstat.gov.ru/ 
Based on the information base presented in Figure 1, it can be concluded that the value of Russia's GDP has dropped significantly in 2020 compared to 2019. The decrease in this indicator is primarily due to the negative consequences of the pandemic. It should be noted that in the first two quarters, the drop in GDP was even more critical, but towards the end of 2020, the situation was somewhat improved. Over the period of the study, the most significant increase in Russia's GDP was noted in 2018 compared to 2017 by $13.09 \%$. In addition, in 2019 compared to 2018 , the progressive dynamics of the country's GDP is also recorded, which found its expression in a positive growth rate of $5.13 \%$. The introduction of foreign economic sanctions did not have a radical impact on the dynamics of the country's GDP, in particular, in 2015 compared to 2014, this indicator increased by 5.13\% [2].

The volatility of the national currency rate has a huge impact on the level of financial risks. The depreciation of the ruble leads to significant negative consequences in the country's financial system, which leads to inflationary growth and disruption of partnership relations, and also increases the likelihood of default on debt obligations. In addition, the depreciation of the ruble contributes to an overall reduction in effective demand in the Russian economy and an increase in the risks of losing liquidity in commercial structures. Within the framework of this study, in Figure 2, we present the dynamics of the exchange rate of the ruble against the US dollar.

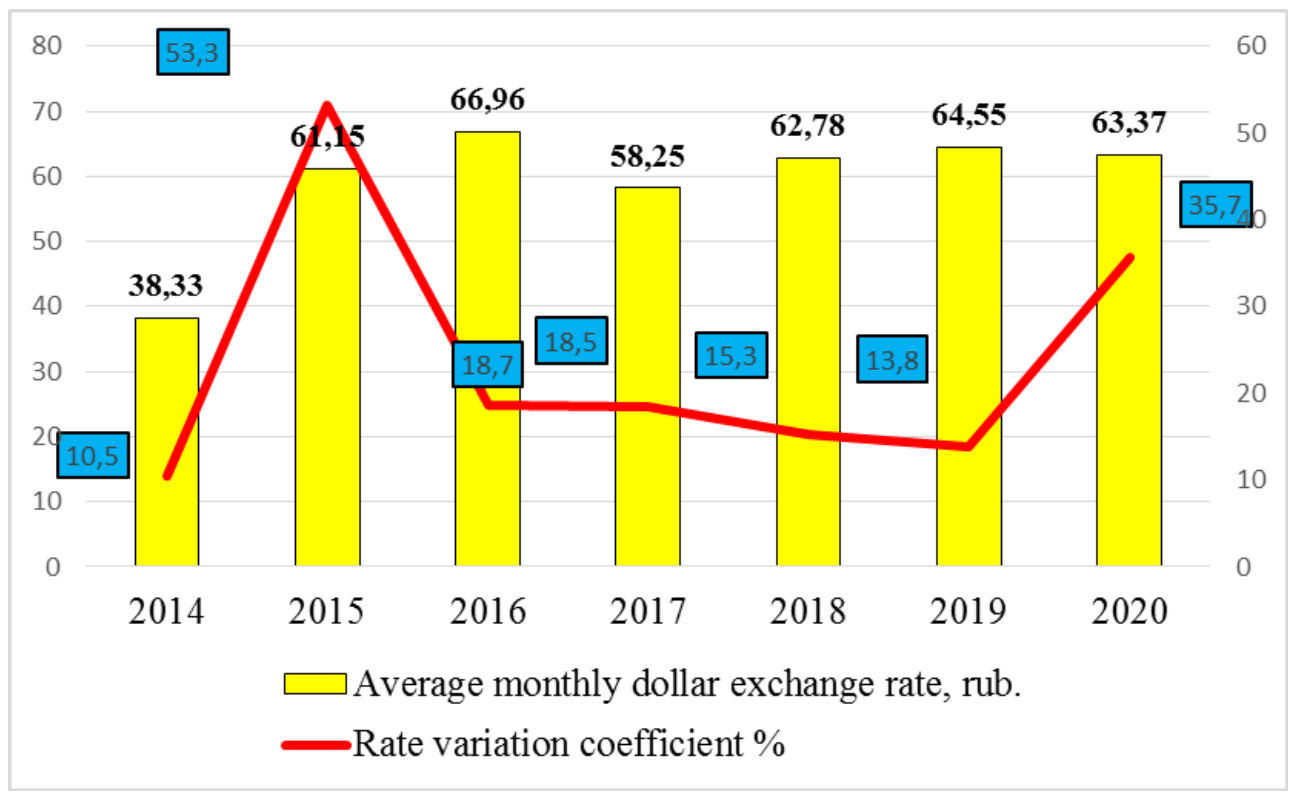

Fig. 2. Dynamics of the exchange rate of the ruble against the US dollar Source: Official website of the Central Bank of the Russian Federation. - URL: https://cbr.ru/

Based on the information presented in Figure 2, it can be concluded that the volatility of the ruble exchange rate is high. During the study period, the dollar has grown significantly. The most significant growth in the dollar exchange rate was observed in 2015 compared to 2014. From the point of view of generating financial risks, the level of volatility of the ruble exchange rate is of particular interest. In this regard, it is worth noting the significant fluctuations in the exchange rate of the national currency in 2015 and 2020 [3]. It is during these time periods that an increased level of growth in the likelihood of the onset of systemic financial risks is recorded.

For the generation of financial risks, the dynamics of the country's securities market is of decisive importance. The overall assessment of the dynamics of the Russian securities market is formed on the basis of diagnostics of key indices that characterize its state. Figure 3 shows the dynamics of the RTS index of the Russian securities market [4]. 


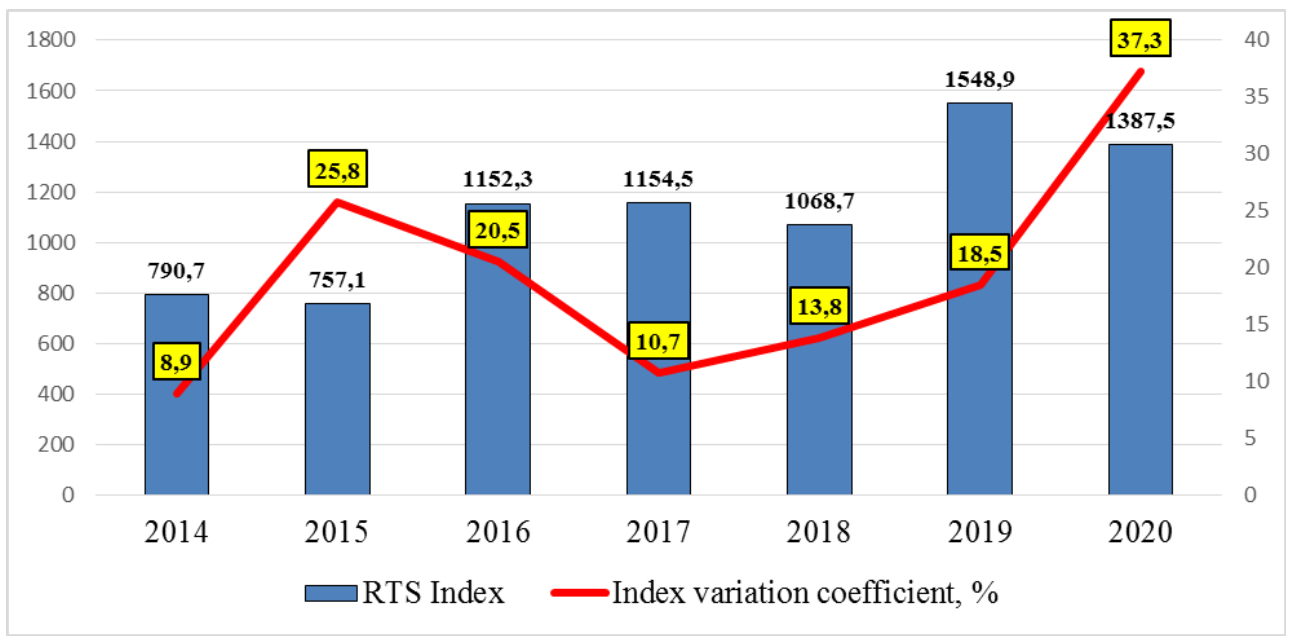

Fig. 3. Dynamics of the RTS index of the Russian securities market

Source: Official website of the RF Ministry of Finance. - URL: https://minfin.gov.ru/ru/

The decline in the development indicators of the securities market in the country indicates a decrease in the investment attractiveness of domestic corporations for both domestic and foreign investors. This circumstance leads to an outflow of capital from the domestic financial market and may create certain difficulties with liquidity. In addition, a decrease in business activity in the securities market leads to a decrease in the capitalization of domestic companies, which also generates significant systemic financial risks.

Based on the presented statistical information, it can be concluded that the progressive development of the Russian securities market for the period 2014-2020, which indicates the growth of capitalization of domestic companies and their financial and economic institutions. At the same time, the significant variability of the monthly average value of the RTS index in 2015 and 2020 attracts attention. In this regard, we can conclude that it is during these periods that a significant increase in the likelihood of financial risks occurs.

Figure 4 shows the dynamics of the inflation rate in the Russian economy.

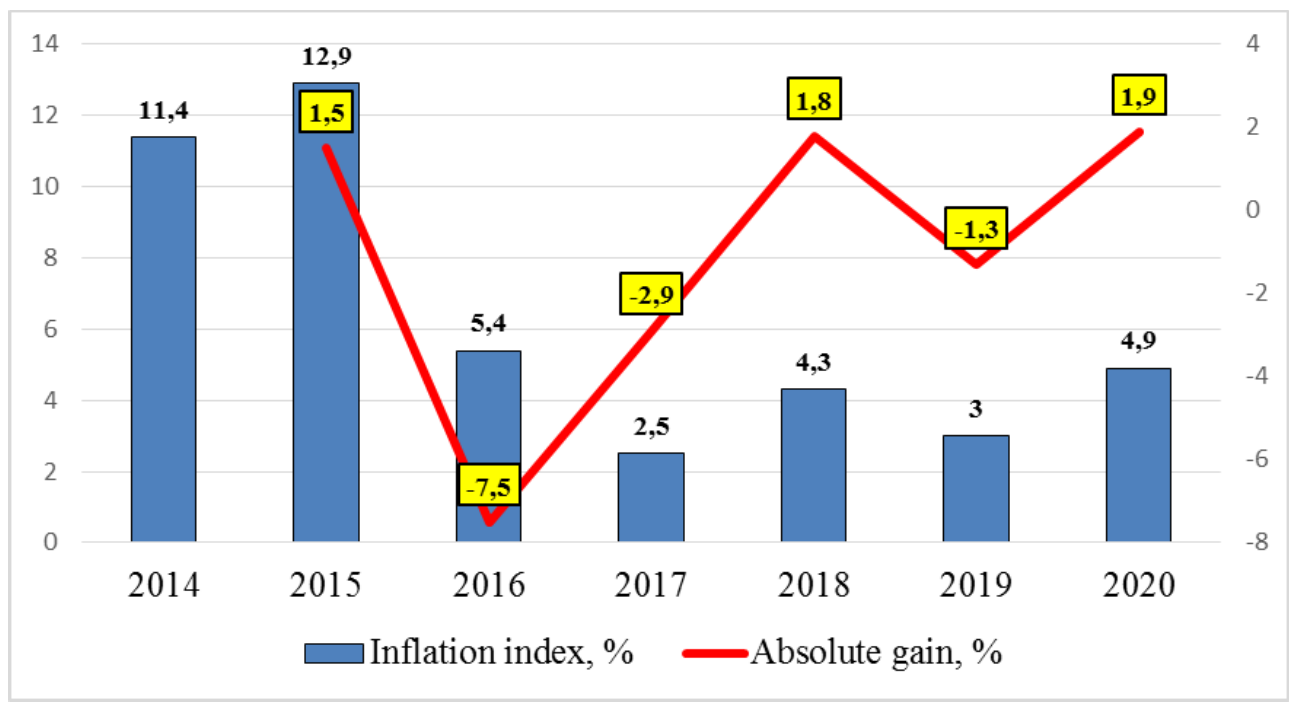

Fig. 4. Inflation dynamics in the Russian economy

Source: Official site of the Ministry of Economic Development of the Russian Federation. [electronic resource]. - URL: https://www.economy.gov.ru/ 
The dynamics of the inflation indicator also has a certain level of relevance in the mechanism for generating financial risks. An increase in inflation leads to a decrease in effective demand in the country, which in turn may become the basis for a slowdown in economic development and the formation of payment gaps. As can be seen from Figure 4, the dynamics of the inflation index in Russia throughout the entire period of the study is highly variable. The maximum inflation rate is recorded in 2015 at $12.9 \%$, and the minimum in 2017 at 3\% [5]. In 2020, amid a pandemic, inflation in Russia remained within the acceptable range of the Ministry of Finance of $4.9 \%$, but this figure increased by $1.9 \%$ compared to the previous year.

\section{Conclusion}

Summarizing the above, we can conclude that the existing macroeconomic dynamics contributes to the generation of systemic financial risks in Russia. The turbulence of the main macroeconomic indicators in 2020 , which is provoked by the consequences of the pandemic, is of particular concern. In this regard, the financial authorities of the state must take all the necessary responsible measures to reduce the likelihood of adverse financial events. The main results of the performed diagnostics revealed the key pain points in the generation of systemic financial risks, which must first of all include a drop in GDP, a high level of volatility in both the securities market and the exchange rate of the domestic currency, as well as an increase in inflation. From the point of view of economic entities of the economic system of Russia, the relevance of the results of the study is determined by the need to increase the intensity of the use of measures aimed at reducing the negative impact of systemic financial risks. In the process of making management decisions by management within the framework of conducting commercial activities and implementing various kinds of projects, the growing likelihood of adverse financial events of a systemic nature should be taken into account. Improving the quality of identification of financial risks in the context of the study is an important factor in expanding the tools for more effective management of them in terms of increasing the economic security of business entities.

\section{References}

1. The main directions of the unified state monetary policy for 2021 and the period of 2022 and 2023 (approved by the Bank of Russia) // SPS "Consultant Plus". - URL: http://www.consultant.ru/document/cons_doc_LAW_366866/0ce1aab1c92dff3b24a68 0 acc8ec8bd0dca5035a/

2. Official site of the Federal State Statistics Service. - URL: https://rosstat.gov.ru/

3. The official website of the Central Bank of the Russian Federation. - URL: https://cbr.ru/

4. The official website of the Ministry of Finance of the Russian Federation. - URL: https://minfin.gov.ru/ru/

5. Official site of the Ministry of Economic Development of the Russian Federation. URL: https://www.economy.gov.ru/ 